\title{
APPROACHES FOR THE CALCULATION OF RAYLEIGH DAMPING COEFFICIENTS FOR A TIME-HISTORY ANALYSIS
}

\author{
VITALIY SERGEEVICH GERASCHENKO, ANDREY SERGEEVICH GRISHIN \& \\ NATALY IGOREVNA GARTUNG \\ Research Department of Dynamics and Seismic Stability of Structures, JSC “Atomenergoproekt”, Russia
}

\begin{abstract}
Direct numerical integration of the differential equations of motion is widely used to analyse a structure behaviour under the action of seismic loads. Whatever the reason is, an engineer is faced with a problem of calculating Rayleigh damping coefficients. In the direct method, a damping matrix is formed by a linear combination of the mass and stiffness matrices multiplied by Rayleigh coefficients $\alpha$ and $\beta$ respectively. To calculate the damping coefficients $\alpha$ and $\beta$, an engineer need two circular frequencies $(\omega 1, \omega 2)$ defining the frequency range which contribute to the response of the structure and a damping ratio $(\xi)$. As far as one knows, Rayleigh damping coefficients have significant impact on the structure response to seismic loads therefore the design values of the damping coefficients should be justified. When the modal superposition method is used, the engineer is able to account accurately for damping, because one can use a material-damping ratio (fraction of critical damping). In this paper, the authors carry out time-history analyses of a fixed base building subjected to seismic loads by the modal superposition and direct integration methods. In the direct method, damping properties of the building are taken into account with Rayleigh damping coefficients calculated on different approaches. The building response to seismic loads are compared by the response spectra calculated upon the timehistories retrieved from the modal superposition and direct methods. The least conservative approach of calculating damping coefficients is proposed for the time-history analysis with Rayleigh damping. Keywords: Rayleigh, damping coefficients, time-history analysis, calculation, response spectrum, FEM, direct method.
\end{abstract}

\section{INTRODUCTION}

A time-history (transient) analysis is used to determine the response of a structure subjected to time-dependent loads considering inertia and damping effects. Contemporary finiteelement programs perform a transient analysis using the full (direct) or modal superposition method. The full method uses full system matrices to calculate the transient response at each solution point, the modal superposition method scales the mode shapes and sums them to capture the dynamic response.

When the dynamic analysis of a structure is performed with the direct method, one can use proportional damping (Rayleigh damping) to take into account the damping properties of the structure. In this case, a damping matrix $[\mathrm{C}]$ is formed by a linear combination of the mass $[\mathrm{M}]$ and stiffness $[\mathrm{K}]$ matrices multiplied by proportional coefficients $\alpha$ and $\beta$ as follows:

$$
[\mathrm{C}]=\alpha[\mathrm{M}]+\beta[\mathrm{K}],
$$

where $\alpha$ and $\beta$ are proportional damping coefficients (Rayleigh coefficients).

The values of $\alpha$ and $\beta$ are not generally known directly, but are calculated from modal damping ratios $\xi_{\mathrm{i}}$ (the ratio of actual damping to critical damping for a particular mode of vibration i). If $\omega_{i}$ is the natural circular frequency of mode $i, \alpha$ and $\beta$ satisfy the relation:

$$
\xi_{\mathrm{i}}=\alpha /\left(2 \omega_{\mathrm{i}}\right)+\beta \omega_{\mathrm{i}} / 2
$$


Rayleigh damping (eqn (1)) produces a total curve that can accurately match modal damping values at one or two natural frequency points. Consequently, if a structure has one or two dominant frequencies, Rayleigh damping is precisely able to approximate the dynamic behaviour of the structure. However, for real structures having many modes over a large range of natural frequencies, Rayleigh damping can lead into significant variations in the response as compared to the use of modal damping.

The aim of the paper is to choose the best approach for the calculation of Rayleigh damping coefficients for the structure subjected to dynamic loads. The comparison is made by the response spectra obtained from the full and modal superposition analyses in which the damping properties of the structure are accurately accounted for.

\section{MATERIALS AND METHODS}

\subsection{Purpose and scope}

Choosing the best approach for the determination of Rayleigh damping coefficients included the following:

a) Development of the finite element model of a Shielded Control Room Building (SCR).

b) Carrying out the modal analysis of the SCR building.

c) Calculation of the Rayleigh damping coefficient for the proposed approaches.

d) Performing the transient analyses of the SCR building by the direct (with the adopted Rayleigh damping coefficients) and modal superposition methods (with a fraction of critical damping).

e) Generation of response spectra for the direct and modal superposition analyses.

f) Comparison of the generated response spectra.

g) Drawing a conclusion on the most optimal approach for the determination of the Rayleigh damping coefficients if the direct numerical integration scheme is being used.

\subsection{Building finite element model}

Shielded Control Room Building (SCR) is designed for managing a nuclear plant under normal and emergency conditions. The SCR building is made of reinforced concrete, except for the partitions, which are made of concrete blocks. The concrete has a strength of $17 \mathrm{MPa}$ and an elasticity modulus of $32.5 \mathrm{GPa}$. The reinforcing steel has a modulus of $200 \mathrm{GPa}$. The SCR building is partly embedded in soil, but in this research, we are not considering it to avoid the influence of soil-structure interaction effects on Rayleigh damping coefficients.

A three-dimensional finite-element model of the SCR building is shown in Fig. 1. The finite-element model is based on the building's design and is meshed with BEAM188 and SHELL181 finite elements. Additional mass of $300 \mathrm{~kg} / \mathrm{m}^{2}$ is evenly spread across the floor elements and $250 \mathrm{~kg} / \mathrm{m}^{2}$ - over the roof elements. Fixed support boundary condition is applied to the foundation elements of the model.

\subsection{Earthquake ground motion}

Seismic input ground motions (vertical and horizontal spectra components) for the Safe Shutdown Earthquake (SSE) are shown in Figs 2 and 3. The predicted intensity of the seismic input ground motions, which are characterized by a horizontal zero-period acceleration, is $0.201 \mathrm{~g}$ for the horizontal component and $0.134 \mathrm{~g}$ for the vertical component. 


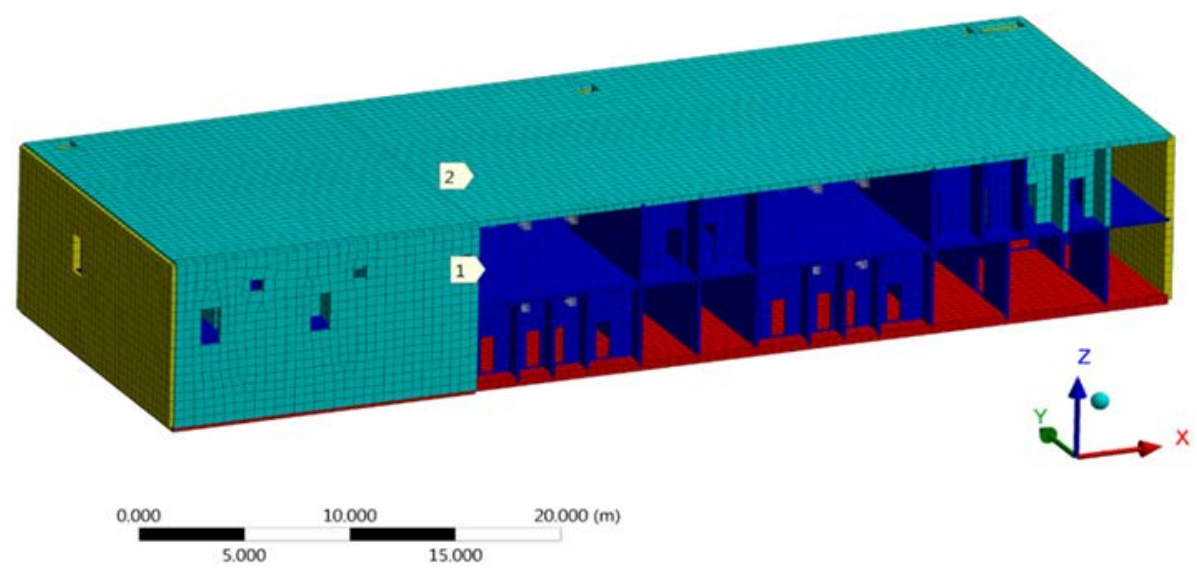

Figure 1: Finite element model of the SCR building. Points notations for response spectra generation. (Thicknesses of shell and beam elements are displayed.)

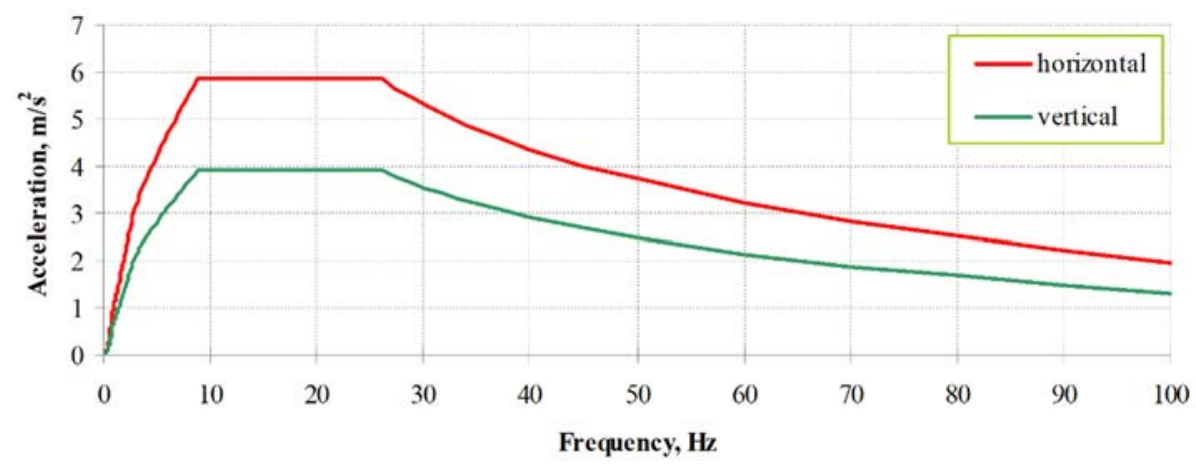

Figure 2: Horizontal and vertical spectra components of the seismic input ground motion.

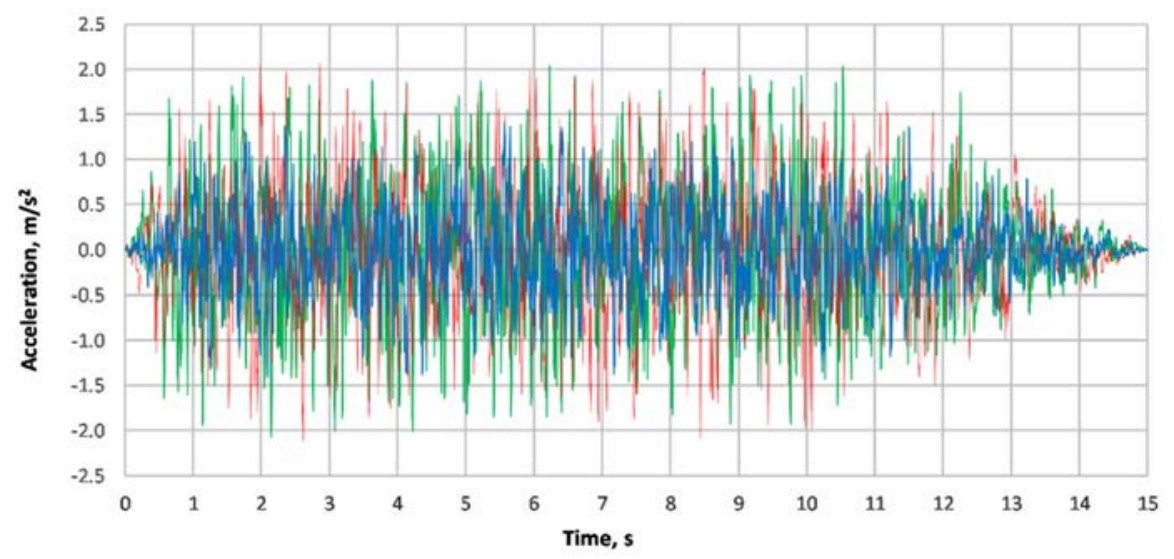

Figure 3: Ground motion three-component accelerogram. 
In Fig. 3 a three-component accelerogram is shown for the SSE seismic input ground motions. The accelerogram is statistically independent; the coefficient of mutual correlation between its components does not exceed 0.1 . The accelerogram time discretization is $0.005 \mathrm{~s}$ that allows us to consider the frequency range up to $100 \mathrm{~Hz}$.

\subsection{Analysis procedures}

\subsubsection{Mode-frequency analysis}

A modal analysis determines the vibration characteristic (natural frequencies and mode shapes) of a structure and serves as a starting point for a transient dynamic analysis.

The equation of motion for an undamped system is [1]:

$$
[\mathrm{M}]\{\ddot{\mathrm{u}}\}+[\mathrm{K}]\{\mathrm{u}\}=\{0\},
$$

where $\{\ddot{\mathrm{u}}\}$ is the nodal acceleration vector; $\{\mathrm{u}\}$ is the nodal displacement vector; $[\mathrm{M}],[\mathrm{K}]-$ as per in eqn (1).

For a linear system, free vibrations will be harmonic of the form:

$$
\{\mathrm{u}\}=\left\{\phi_{\mathrm{i}}\right\} \cos \omega_{\mathrm{i}} \mathrm{t},
$$

where $\left\{\phi_{\mathrm{i}}\right\}$ is the eigenvector representing the mode shape of the ith natural frequency; $\omega_{\mathrm{i}}$ is the ith natural circular frequency; $t$ is time.

Thus, eqn (3) becomes:

$$
\left(-\omega_{\mathrm{i}}^{2}[\mathrm{M}]+[\mathrm{K}]\right)\left\{\phi_{\mathrm{i}}\right\}=\{0\} .
$$

This equality is satisfied if either $\left\{\phi_{\mathrm{i}}\right\}=\{0\}$ or if the determinant of $\left(-\omega_{\mathrm{i}}{ }^{2}[\mathrm{M}]+[\mathrm{K}]\right)$ is zero. The first option is the trivial one and, therefore, is not interest. Thus, the second one gives the solution:

$$
\left|[\mathrm{K}]-\omega_{\mathrm{i}}^{2}[\mathrm{M}]\right|=0 .
$$

The problem in eqn (6) is solved with the Block Lanczos eigenvalue extraction method.

\subsubsection{Transient analysis}

For most linear structural dynamics problems of a mechanical system, the spatial discretization for the principle of virtual work using the finite element method gives the finite element semi-discrete equations of motion as follows:

$$
[\mathrm{M}]\{\ddot{\mathrm{u}}(\mathrm{t})\}+[\mathrm{C}]\{\dot{\mathrm{u}}(\mathrm{t})\}+[\mathrm{K}]\{\mathrm{u}(\mathrm{t})\}=\left\{\mathrm{F}^{\mathrm{a}}(\mathrm{t})\right\}
$$

where $[\mathrm{M}]$ is the structural mass matrix; $[\mathrm{C}]$ is the structural damping matrix; $[\mathrm{K}]$ is the structural stiffness matrix; $\{\ddot{\mathrm{u}}(\mathrm{t})\}$ is the nodal acceleration vector; $\{\dot{\mathrm{u}}(\mathrm{t})\}$ is the nodal velocity vector; $\{\mathrm{u}(\mathrm{t})\}$ is the nodal displacement vector; $\left\{\mathrm{F}^{\mathrm{a}}(\mathrm{t})\right\}$ is the applied load vector.

Numerical solving the finite element semi-discrete equation of motion given in eqn (7) is employed with implicit time integration scheme using the Newmark method. The Newmark integration depends on two real parameters $\delta$ and $\alpha$ and they are equal $1 / 2$ and $1 / 4$, respectively [1]. Two methods of solution for the Newmark method are available: full and mode-superposition.

For full-based analyses, the damping matrix [C] is calculated from eqn (1) with specified Rayleigh damping coefficients.

For mode-superposition (MSUP) based analyses, the damping matrix [C] is not explicitly calculated, but rather the damping is defined directly in terms of a damping ratio $\xi^{\mathrm{d}}$. The 
damping ratio is the ration between actual damping and critical damping. The damping ratio $\xi_{i}^{d}$ for mode $\mathrm{i}$ is the combination of:

$$
\xi_{i}^{\mathrm{d}}=\xi+\xi_{i}^{\mathrm{m}}+\frac{\alpha}{2 \omega_{\mathrm{i}}}+\frac{\beta}{2} \omega_{\mathrm{i}},
$$

where $\xi$ is a constant modal damping ratio; $\xi_{i}^{m}$ is the modal damping ratio for mode shape $i$; $\omega_{\mathrm{i}}$ is the circular natural frequency associated with mode shape $\mathrm{i}=2 \pi \mathrm{f}_{\mathrm{i}} ; \mathrm{f}_{\mathrm{i}}$ is the natural frequency associated with mode shape $i ; \alpha, \beta$ are mass and stiffness matrix multipliers respectively.

\subsection{Approaches to the calculation of Rayleigh damping coefficients}

To define Rayleigh damping coefficients eqn (1) to carry out a full transient analysis, an engineer may use a variety of approaches. The most frequently used of them are described subsequently.

\subsubsection{Conventional approach (CA)}

In this approach, given $\xi$ and frequency range $\omega_{\min }$ and $\omega_{\max }$, two simultaneous equations (eqn (2)) can be solved for $\alpha$ and $\beta$ :

$$
\alpha=2 \xi \frac{\omega_{\max } \omega_{\min }}{\omega_{\max }+\omega_{\min }} ; \beta=\frac{2 \xi}{\omega_{\max }+\omega_{\min }},
$$

where $\xi$ is the damping ratio (this value is indicated in National Regulatory Guides); $\omega_{\min }$ is the first undamped circular frequency of the structure; $\omega_{\max }$ is the last undamped circular frequency which contributes to the response of the structure.

\subsubsection{Least squares method approaches}

The method of least squares is a standard approach to approximate the solution of overdetermined systems, i.e. sets of equations in which there are more equations than unknowns. Since the number of natural modes of a real structure almost always exceed the number of unknowns, the method of least squares is adopted for the calculation of Rayleigh damping coefficients ( $\alpha$ and $\beta$ ).

Problem statement. The goal is to find Rayleigh damping coefficients for a structure that "best" fits the data. The fit of the structure to a data point is measured by its residual, defined as the difference between the design value of damping ratio $(\psi)$ and the value predicted by the approach used for the specified frequency range:

$$
\mathrm{r}_{\mathrm{i}}=\psi-\xi_{\mathrm{i}} .
$$

The least squares method finds the optimal parameter values by minimizing the sum, S, of squared residuals for each mode shape i:

$$
\mathrm{S}=\sum_{\mathrm{i}=1}^{\mathrm{N}} \mathrm{r}_{\mathrm{i}}^{2} \text {. }
$$

Solving the least squares problem. The minimum of the sum of squares is found by setting the gradient to zero. Since the Rayleigh damping model contains two coefficients, there are two gradient equations:

$$
\left\{\begin{array}{l}
\frac{\partial \mathrm{S}}{\partial \alpha}=2 \sum_{\mathrm{i}=1}^{\mathrm{N}} \mathrm{r}_{\mathrm{i}} \frac{\partial \mathrm{r}_{\mathrm{i}}}{\partial \alpha}=0 \\
\frac{\partial \mathrm{S}}{\partial \beta}=2 \sum_{\mathrm{i}=1}^{\mathrm{N}} \mathrm{r}_{\mathrm{i}} \frac{\partial \mathrm{r}_{\mathrm{i}}}{\partial \beta}=0
\end{array}\right.
$$


In the subsequent methods of approaches the different types of objective function, $\mathrm{S}$ is considered [2], [3].

- Pure approach (PA). The objective function, S takes the following form:

$$
\mathrm{S}=\sum_{\mathrm{i}=1}^{\mathrm{N}}\left(\frac{\alpha}{2 \omega_{\mathrm{i}}}+\frac{\beta \omega_{\mathrm{i}}}{2}-\psi\right)^{2} .
$$

The system of equations (eqn (12)) for the objective function (eqn (13)) is written as:

$$
\left\{\begin{array}{l}
\frac{\partial S}{\partial \alpha}=\sum_{i=0}^{N} \frac{1}{\omega_{i}}\left(\frac{\alpha}{2 \omega_{i}}+\frac{\beta \omega_{i}}{2}-\psi\right)=0 ; \\
\frac{\partial S}{\partial \beta}=\sum_{i=0}^{N} \omega_{i}\left(\frac{\alpha}{2 \omega_{i}}+\frac{\beta \omega_{i}}{2}-\psi\right)=0 .
\end{array}\right.
$$

The solution of the system (eqn (14)) for $\alpha$ and $\beta$ is:

$$
\left\{\begin{array}{c}
\alpha=\frac{2\left(\sum_{\mathrm{i}=1}^{\mathrm{N}} \frac{\psi}{\omega_{\mathrm{i}}} \sum_{\mathrm{i}=1}^{\mathrm{N}} \omega_{\mathrm{i}}^{2}-\mathrm{N} \sum_{\mathrm{i}=1}^{\mathrm{N}} \psi \omega_{\mathrm{i}}\right)}{\sum_{\mathrm{i}=1}^{\mathrm{N}} \frac{1}{\omega_{\mathrm{i}}^{2}} \sum_{\mathrm{i}=1}^{\mathrm{N}} \omega_{\mathrm{i}}^{2}-\mathrm{N}^{2}} \\
\beta=\frac{2\left(\sum_{\mathrm{i}=1}^{\mathrm{N}} \frac{1}{\omega_{\mathrm{i}}^{2}} \sum_{\mathrm{i}=1}^{\mathrm{N}} \psi \omega_{\mathrm{i}}-\mathrm{N} \sum_{\mathrm{i}=1}^{\mathrm{N}} \frac{\psi}{\omega_{\mathrm{i}}}\right)}{\sum_{\mathrm{i}=1}^{\mathrm{N}} \frac{1}{\omega_{\mathrm{i}}^{2}} \sum_{\mathrm{i}=1}^{\mathrm{N}} \omega_{\mathrm{i}}^{2}-\mathrm{N}^{2}}
\end{array}\right.
$$

- Inverse frequency weighted approach (IFWA). The objective function is taken as:

$$
S=\sum_{i=1}^{N} \frac{1}{\omega_{i}}\left(\frac{\alpha}{2 \omega_{i}}+\frac{\beta \omega_{i}}{2}-\psi\right)^{2} .
$$

The system of equations (eqn (12)) for the objective function (eqn (16)) is written as:

$$
\left\{\begin{array}{l}
\frac{\partial S}{\partial \alpha}=\sum_{\mathrm{i}=0}^{\mathrm{N}} \frac{1}{\omega_{\mathrm{i}}}\left(\frac{\alpha}{2 \omega_{\mathrm{i}}^{2}}+\frac{\beta}{2}-\frac{\psi}{\omega_{\mathrm{i}}}\right)=0 ; \\
\frac{\partial \mathrm{S}}{\partial \beta}=\sum_{\mathrm{i}=0}^{\mathrm{N}}\left(\frac{\alpha}{2 \omega_{\mathrm{i}}}+\frac{\beta \omega_{\mathrm{i}}}{2}-\psi\right)=0 .
\end{array}\right.
$$

The solution of the system (eqn (17)) for $\alpha$ and $\beta$ is:

$$
\left\{\begin{array}{c}
\alpha=\frac{2\left(\sum_{\mathrm{i}=1}^{\mathrm{N}} \omega_{\mathrm{i}} \sum_{\mathrm{i}=1}^{\mathrm{N}=1} \frac{\psi}{\omega_{\mathrm{i}}^{2}} \sum_{\mathrm{i}=1}^{\mathrm{N}} \xi \psi \sum_{\mathrm{i}=1}^{\mathrm{N}} \frac{1}{\omega_{\mathrm{i}}}\right)}{\sum_{\mathrm{i}=1}^{\mathrm{N}} \frac{1}{\omega_{\mathrm{i}}^{3}} \sum_{\mathrm{i}=1}^{\mathrm{N}} \omega_{\mathrm{i}}-\sum_{\mathrm{i}=1}^{\mathrm{N}} \frac{1}{\omega_{\mathrm{i}}} \sum_{\mathrm{i}=1}^{\mathrm{N}} \frac{1}{\omega_{\mathrm{i}}}} \\
\beta=\frac{2\left(\sum_{\mathrm{i}=1}^{\mathrm{N}} \frac{1}{\omega_{\mathrm{i}}^{3}} \sum_{\mathrm{i}=1}^{\mathrm{N}} \psi-\sum_{\mathrm{i}=1}^{\mathrm{N}} \frac{1}{\omega_{\mathrm{i}}} \sum_{\mathrm{i}=1}^{\mathrm{N}} \frac{\psi}{\omega_{\mathrm{i}}^{2}}\right)}{\sum_{\mathrm{i}=1}^{\mathrm{N}} \frac{1}{\omega_{\mathrm{i}}^{3}} \sum_{\mathrm{i}=1}^{\mathrm{N}} \omega_{\mathrm{i}}-\sum_{\mathrm{i}=1}^{\mathrm{N}} \frac{1}{\omega_{\mathrm{i}}} \sum_{\mathrm{i}=1}^{\mathrm{N}} \frac{1}{\omega_{\mathrm{i}}}} .
\end{array}\right.
$$

- Mass participation weighted approach (MPWA). The objective function is taken as:

$$
\mathrm{S}=\sum_{\mathrm{i}=1}^{\mathrm{N}} \frac{\mathrm{m}_{\mathrm{i}}}{\mathrm{M}}\left(\frac{\alpha}{2 \omega_{\mathrm{i}}}+\frac{\beta \omega_{\mathrm{i}}}{2}-\psi\right)^{2}
$$

The system of equations (eqn (12)) for the objective function (eqn (19)) is:

$$
\left\{\begin{array}{c}
\frac{\partial S}{\partial \alpha}=\frac{1}{M} \sum_{i=0}^{N}\left(\frac{\alpha m_{i}}{2 \omega_{i}^{2}}+\frac{\beta m_{i}}{2}-\frac{\psi m_{i}}{\omega_{i}}\right)=0 \\
\frac{\partial S}{\partial \beta}=\frac{1}{M} \sum_{i=0}^{N}\left(\frac{\alpha m_{i}}{2}+\frac{\beta \omega_{i}^{2} m_{i}}{2}-\psi \omega_{i} m_{i}\right)=0 .
\end{array}\right.
$$

The solution of the system (eqn (20)) for $\alpha$ and $\beta$ is: 


$$
\left\{\begin{array}{c}
\alpha=\frac{\sum_{i=1}^{\mathrm{N}} \frac{\omega_{\mathrm{i}}^{2} \mathrm{~m}_{\mathrm{i}}}{2} \sum_{\mathrm{i}=1}^{\mathrm{N}} \frac{\psi \mathrm{m}_{\mathrm{i}}}{\omega_{\mathrm{i}}} \sum_{\mathrm{i}=1}^{\mathrm{N}} \psi \mathrm{m}_{\mathrm{i}} \omega_{\mathrm{i}} \sum_{\mathrm{i}=1}^{\mathrm{N}} \frac{\mathrm{m}_{\mathrm{i}}}{2}}{\sum_{\mathrm{i}=1}^{\mathrm{N}} \frac{\mathrm{m}_{\mathrm{i}}}{2 \omega_{\mathrm{i}}^{2}} \sum_{\mathrm{i}=1}^{\mathrm{N}} \frac{\mathrm{m}_{\mathrm{i}}}{2 \omega_{\mathrm{i}}^{2}}-\sum_{\mathrm{i}=1}^{\mathrm{N}} \frac{\mathrm{m}_{\mathrm{i}}}{2} \sum_{\mathrm{i}=1}^{\mathrm{N}} \frac{\mathrm{m}_{\mathrm{i}}}{2}} \\
\beta=\frac{\sum_{\mathrm{i}=1}^{\mathrm{N}} \xi \mathrm{m}_{\mathrm{i}} \omega_{\mathrm{i}} \sum_{\mathrm{i}=1}^{\mathrm{N}} \frac{\mathrm{m}_{\mathrm{i}}}{2 \omega_{\mathrm{i}}^{2}}-\sum_{\mathrm{i}=1}^{\mathrm{N}} \frac{\mathrm{m}_{\mathrm{i}}}{2} \sum_{\mathrm{i}=1}^{\mathrm{N}} \frac{\xi \mathrm{m}_{\mathrm{i}}}{\omega_{\mathrm{i}}}}{\sum_{\mathrm{i}=1}^{\mathrm{N}} \frac{\mathrm{m}_{\mathrm{i}}}{2 \omega_{\mathrm{i}}^{2}} \sum_{\mathrm{i}=1}^{\mathrm{N}} \frac{\mathrm{m}_{\mathrm{i}}}{2 \omega_{\mathrm{i}}^{2}}-\sum_{\mathrm{i}=1}^{\mathrm{N}} \frac{\mathrm{m}_{\mathrm{i}}}{2} \sum_{\mathrm{i}=1}^{\mathrm{N}} \frac{\mathrm{m}_{\mathrm{i}}}{2}} .
\end{array}\right.
$$

\section{RESULTS}

\subsection{Modal analysis}

The results of the modal analysis of the SCR building are given in Table 1. The predominant translational and rotational mode shapes up to $106.8 \mathrm{~Hz}$ of the building are shown in Fig. 4.

\subsection{Rayleigh damping coefficients for the approaches considered}

According to the approaches described in Section 2.5, the values of Rayleigh damping coefficients are given in Table 2, the corresponding damping curves are shown in Fig. 5.

Table 1: Vibration characteristics of the SCR building.

\begin{tabular}{|c|c|c|c|c|c|c|}
\hline $\begin{array}{c}\text { Mode } \\
\text { shape \# }\end{array}$ & $\mathrm{f}_{\mathrm{i}}, \mathrm{Hz}$ & $\omega_{\mathrm{i}}, \mathrm{rad} / \mathrm{s}$ & $\mathrm{m}_{\mathrm{xi}}, \mathrm{kg}$ & $\mathrm{m}_{\mathrm{yi}}, \mathrm{kg}$ & $\mathrm{m}_{\mathrm{zi}}, \mathrm{kg}$ & $\mathrm{m}_{\mathrm{i}}, \mathrm{kg}$ \\
\hline 1 & 15.64 & 98.22 & $2.60 \mathrm{E}-01$ & $4.06 \mathrm{E}+01$ & $2.35 \mathrm{E}+03$ & $2.35 \mathrm{E}+03$ \\
\hline 2 & 15.68 & 98.47 & $2.18 \mathrm{E}+00$ & $2.95 \mathrm{E}+01$ & $1.18 \mathrm{E}+05$ & $1.18 \mathrm{E}+05$ \\
\hline 3 & 17.41 & 109.31 & $5.84 \mathrm{E}+00$ & $7.00 \mathrm{E}+02$ & $2.34 \mathrm{E}+04$ & $2.34 \mathrm{E}+04$ \\
\hline 5 & 21.10 & 132.51 & $6.96 \mathrm{E}+02$ & $2.83 \mathrm{E}+06$ & $3.18 \mathrm{E}+02$ & $2.83 \mathrm{E}+06$ \\
\hline 11 & 27.16 & 170.57 & $2.24 \mathrm{E}+06$ & $2.63 \mathrm{E}+02$ & $1.23 \mathrm{E}+02$ & $2.24 \mathrm{E}+06$ \\
\hline 108 & 50.83 & 319.23 & $1.25 \mathrm{E}+03$ & $2.48 \mathrm{E}+03$ & $7.92 \mathrm{E}+04$ & $7.93 \mathrm{E}+04$ \\
\hline 500 & 106.80 & 670.73 & $3.42 \mathrm{E}+01$ & $1.27 \mathrm{E}+02$ & $1.14 \mathrm{E}+01$ & $1.32 \mathrm{E}+02$ \\
\hline \multicolumn{7}{|c|}{ Total mass of the building $0.505 \mathrm{E}+07 \mathrm{~kg}$} \\
\hline
\end{tabular}




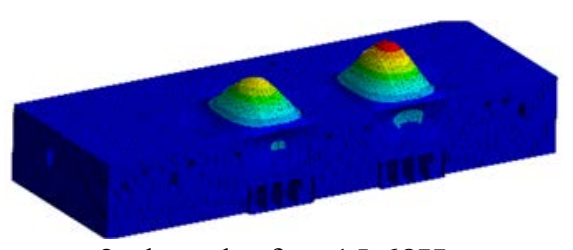

2nd mode, $\mathrm{f}_{2}=15.68 \mathrm{~Hz}$. z-direction.

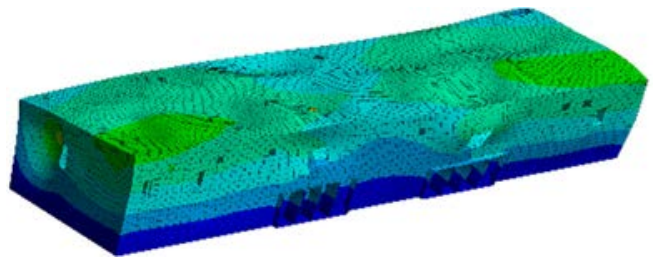

11th mode, $\mathrm{f}_{11}=27.16 \mathrm{~Hz}$. $\mathrm{x}$-direction.

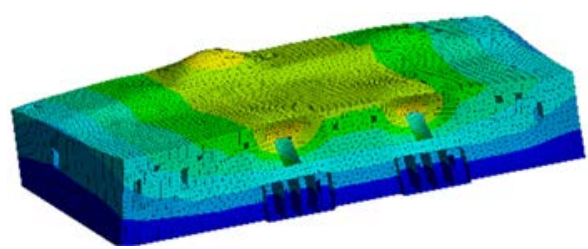

5th mode, $\mathrm{f}_{5}=21.10 \mathrm{~Hz}$. $\mathrm{y}$-direction; $\mathrm{x}, \mathrm{z}$-rotation.

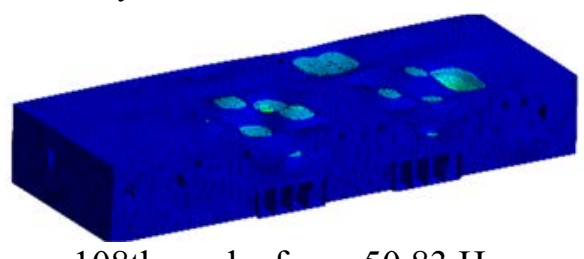

108th mode, $\mathrm{f}_{108}=50.83 \mathrm{~Hz}$. y-rotation.

Figure 4: Predominant mode shapes of the SCR building.

Table 2: Rayleigh damping coefficients at damping ratio $\psi=0.07$.

\begin{tabular}{|l|c|c|c|}
\hline \multirow{2}{*}{ Calculation approach } & \multicolumn{2}{|c|}{ Rayleigh damping coefficients } & \multirow{2}{*}{ Formula } \\
\cline { 2 - 3 } & $\alpha$ & $\beta$ & \multirow{2}{*}{ Eqn (9) } \\
\hline Conventional (CA) & 11.8909 & 0.000193 & \multirow{2}{*}{ Eqn (15) } \\
\hline \multicolumn{3}{|c|}{ Least squares method: } \\
\hline - Pure approach (Pure) & 21.3970 & 0.000187 & Eqn (18) \\
\hline $\begin{array}{l}\text { - Inverse frequency weighted } \\
\text { approach (IFWA) }\end{array}$ & 17.9289 & 0.000209 & Eqn (21) \\
\hline $\begin{array}{l}\text { - Mass participation weighted } \\
\text { approach (MPWA) }\end{array}$ & 15.3401 & 0.000242 & \\
\hline
\end{tabular}

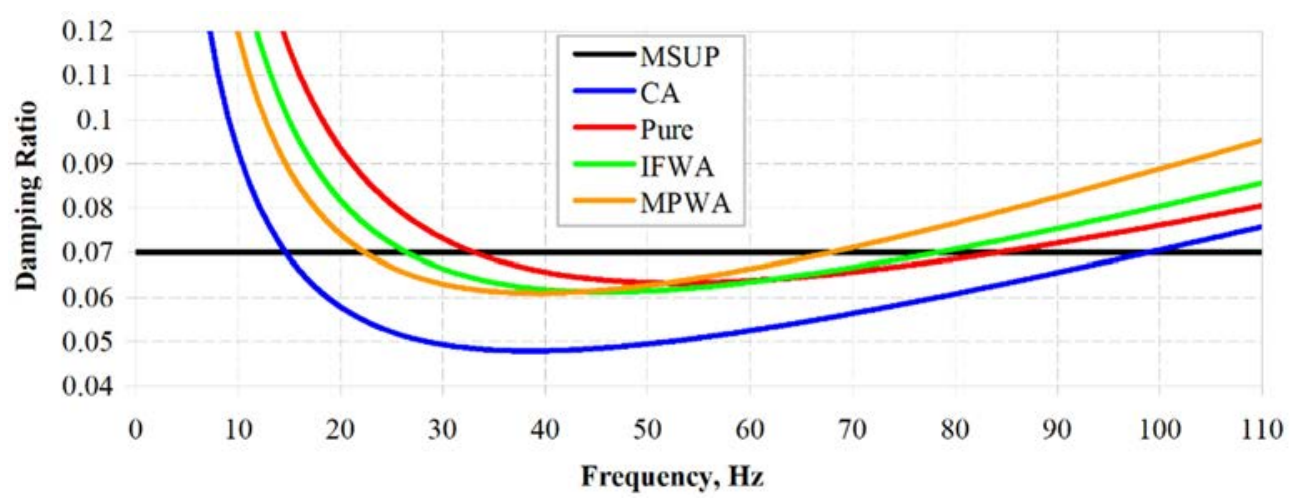

Figure 5: Rayleigh damping curves for the proposed approaches. 


\subsection{Response spectra}

Two percent response spectra are generated for the points shown in Fig. 1. An MSUP curve represents the reference response spectrum since the damping is accurately taken into account by the modal superposition method. CA, Pure, IFWA and MPWA curves depict the response spectra generated upon the direct method with Rayleigh damping coefficients shown in Table 2.

The corresponding response spectra are shown for point 1, 2 in Figs 6 and 7.

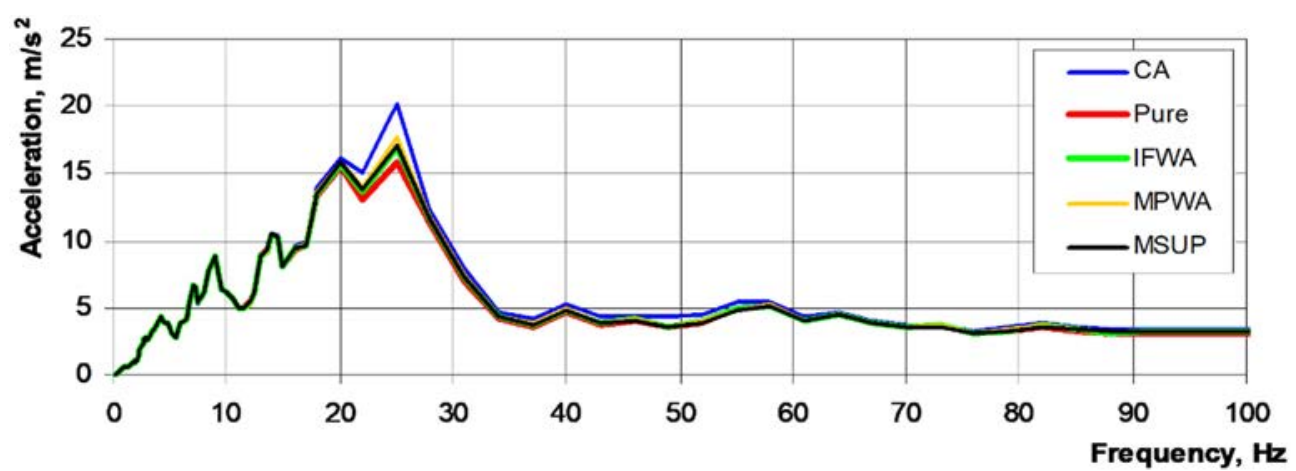

(a) Along horizontal axis $\mathrm{x}$.

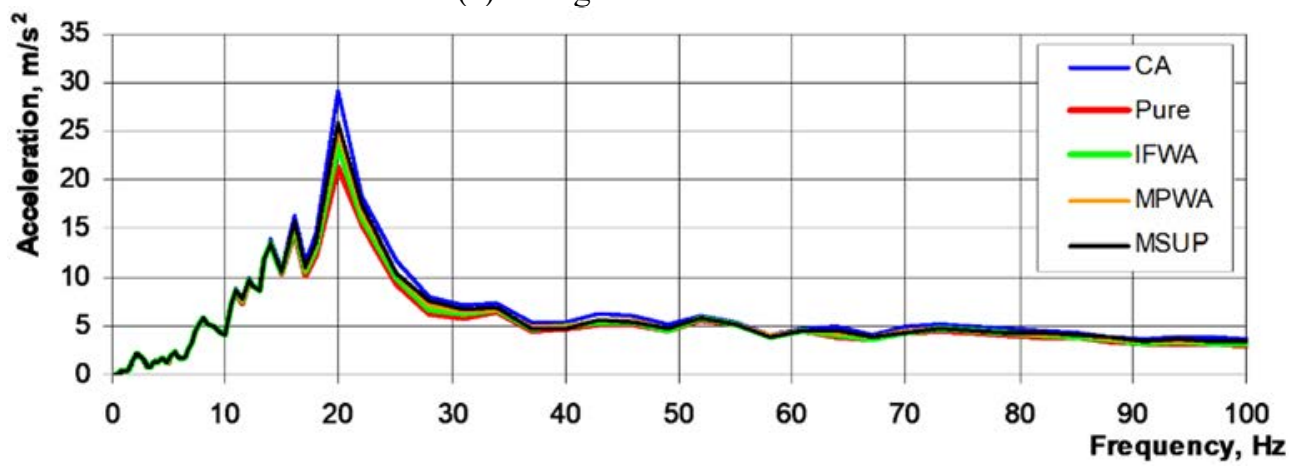

(b) Along horizontal axis y.

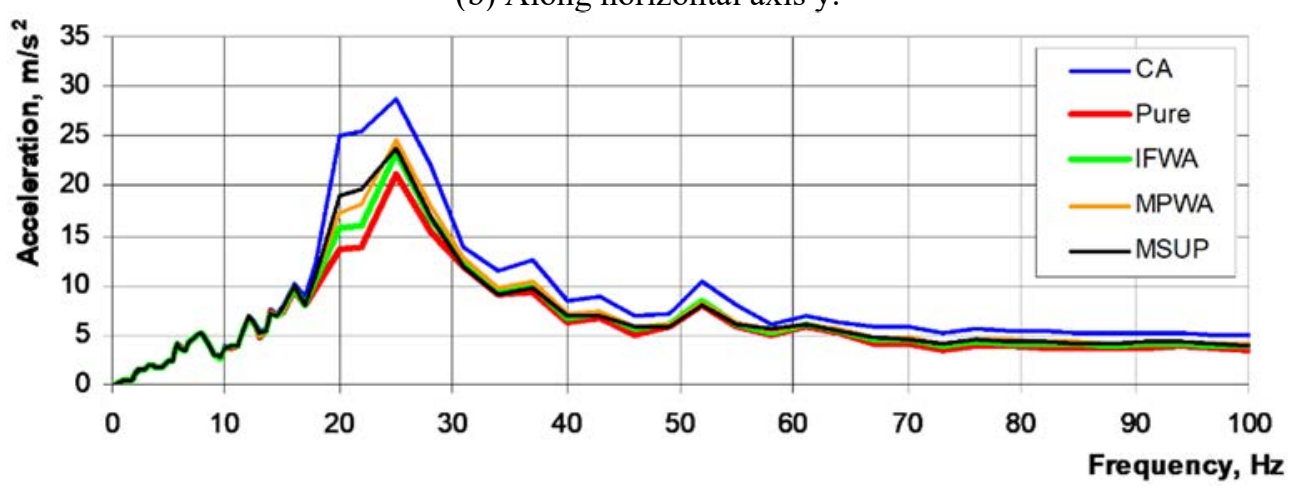

(c) Along vertical axis z.

Figure 6: Response spectrum at point 1. 


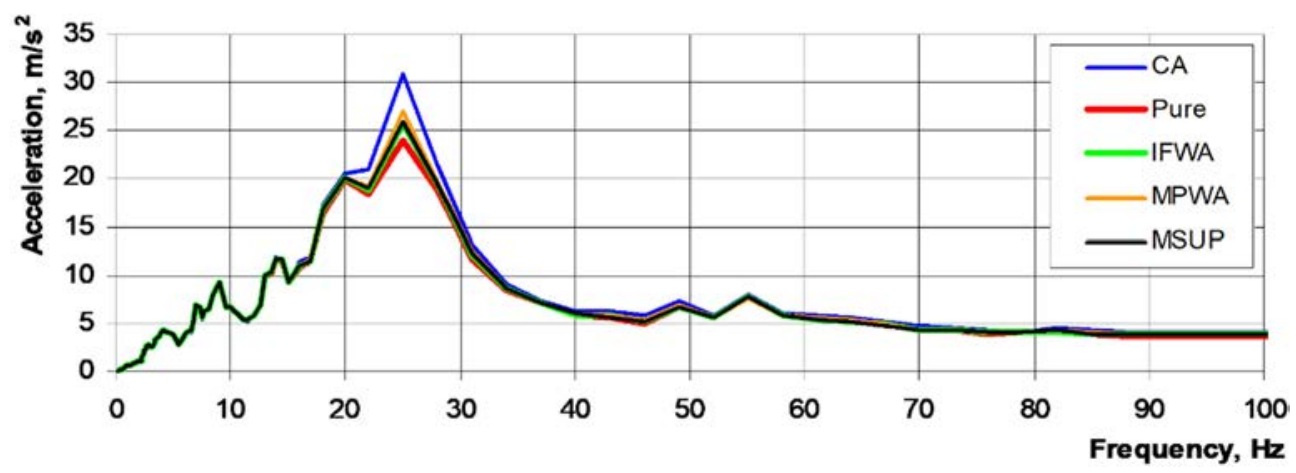

(a) Along horizontal axis $\mathrm{x}$.

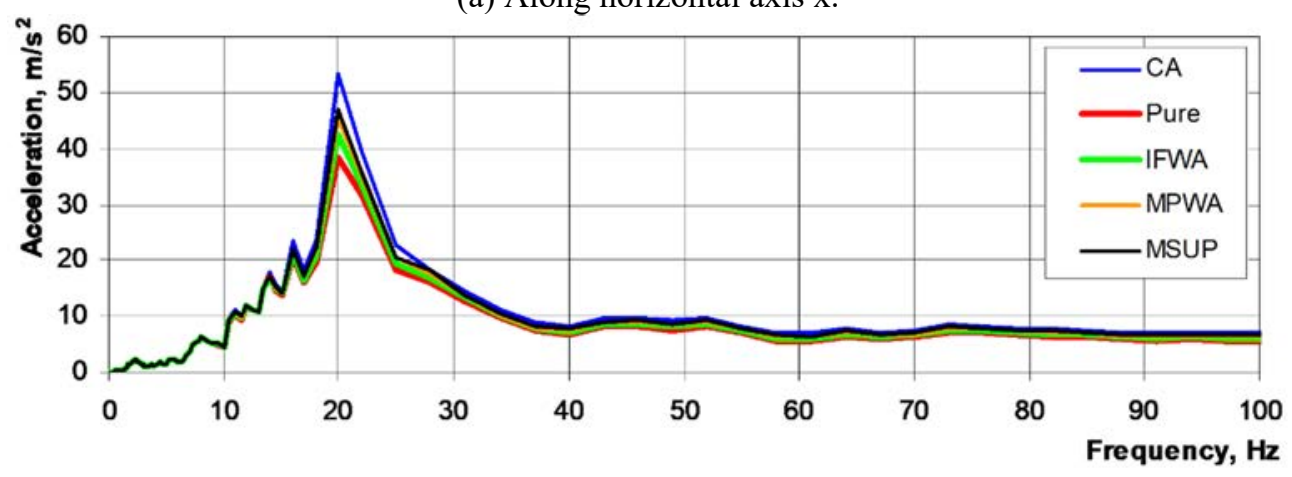

(b) Along horizontal axis y.

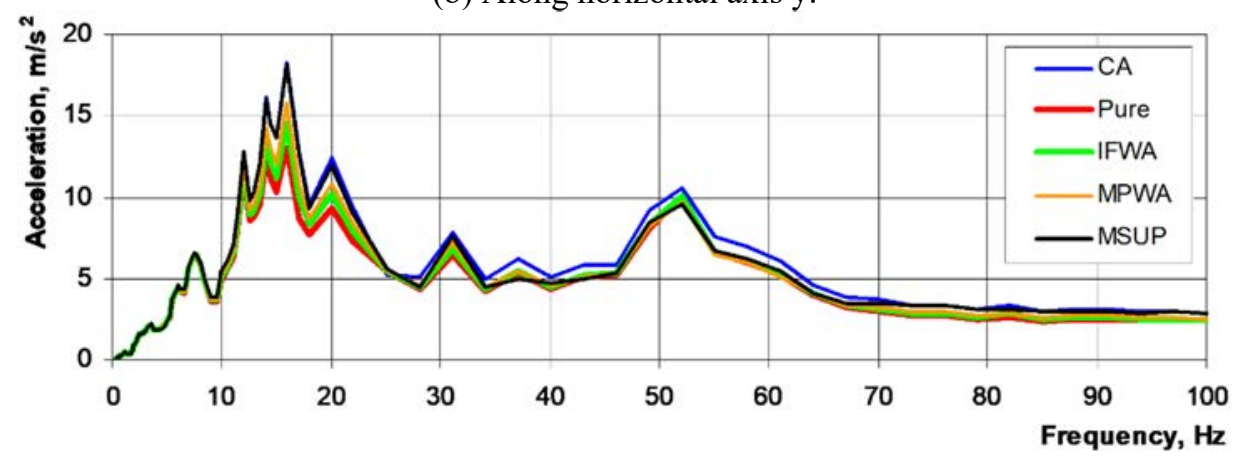

(c) Along vertical axis z.

Figure 7: Response spectrum at point 2.

\section{DISCUSSION}

Choosing Rayleigh damping coefficients need to be addressed in a full dynamic analysis. Four approaches for the evaluation of Rayleigh damping coefficients were proposed. A series of transient analyses of SCR building were performed by the full and modal superposition methods.

Among the approaches considered, the closest to the exact (MSUP) solution is MPWA. While the maximum values of spectral accelerations for each approach considered are very 
close. We assume that this is due to the high frequency of the first mode of vibration of the building.

More general recommendations on Rayleigh damping coefficients' selection require additional research that includes effects from soil-structure interaction and (or) more flexible structures of the building.

\section{REFERENCES}

[1] Ansys Inc., ANSYS Documentation, Release 19.1, 2018.

[2] Zhiqiang, S. \& Chenhui, S., Computation of Rayleigh damping coefficients for the seismic analysis of a hydro-powerhouse. Shock and Vibration, 2017, 2017. DOI: https://doi.org/10.1155/2017/2046345. Accessed on: 27 Jul. 2017.

[3] Huai-Feng, W., Meng-Lin, L. \& Ru-Lin Z., Selection of Rayleigh damping coefficients for seismic response analysis of soil layers. International Journal of Geological and Environmental Engineering, 11(2), pp. 158-163, 2017. https://waset.org/publications/ 10006399. 